\title{
The Impact of Social Media on Students' Time Consumption outside the Classroom
}

\author{
Chaiwat Tantarangsee, Nithiwadee Kosarussawadee, and Aungkana Sukwises
}

\begin{abstract}
The purposes of this study are 1) to find out the amount of time the students spend on the Internet per day, and 2) to study the social media-based activities most frequently conducted in English by the students. Samples include 78 3rd year students in English Major, Faculty of Humanities and Social Sciences, Suan Sunandha Rajabhat University, Bangkok, Thailand. Data was collected by using a questionnaire. The statistics employed include percentage, Mean, and S.D. The research discloses that most of the students spend the average of 6-8 hours per day surfing the Internet followed by more than 8 hours, 4-6 hours, 2-4 hours, and less than 2 hours respectively. Moreover, social media-based activities most frequently conducted in English by the students in high level with the average of 6-8 hours per day include watching cartoon with English soundtrack from websites, using online dictionary to solve linguistic problems, reading comments in English from blogs and forums, and watching entertainment and documentaries with English soundtrack from websites. It can be concluded that social media supports autonomous learning in English based on learners' interest at any place and any time depending on their self- regulations, and encouragement from classroom instruction.
\end{abstract}

Index Terms-Internet users, social media, social media-based activities, students' time consumption.

\section{INTRODUCTION}

Due to the fast growing Information Communication Technology, English is a vital tool for communication among people around the world. That is because the Internet or enables an important event happening in a part of the world to be simultaneously and clearly broadcast to people in other parts of the world with pictures, texts, and video clip, etc. [1] People with different races who speak different languages can consume the same piece of information or news, and share it to other internet users or netizens, and of course the core language used on the internet or websites is English language. [2] That's why English is regarded as "World Language", or "Global Language". [3] The impact of English as World Language on Thai students learning English language is that channel of the communication is not between Thais and native speakers of English, but between Thais and other non-native speakers of English. [4] Moreover, the communication channel does not lie on face to face communication, but it mostly lies on reading, writing, and sharing text messages with photos and clips on social media

Manuscript received June 12, 2016; revised December 9, 2016. The paper was submitted on August 2nd, 2016 and was supported in part by Suan Sunandha Rajabhat Univeristy, Bangkok, Thailand.

The authors are with Suan Sunandha Rajabhat University, Bangkok, Thailand (e-mail ceewattantar@yahoo.com, nithiwadeek@yahoo.com, aungko99@hotmail.com). tools, such as Line and Facebook for communication. Nowadays it is usual to see teenagers and working people in public places using their mobile phones attentively paying no attention to others or circumstances nearby. This leads to the term "Texting Generation" referring to young generation who excessively love texting messages to one another anywhere and anytime without the care to the world. [5]

Since time passes, the need of the internet users has been satisfied more and more by the development of web technology from 1.0 - webs presenting only texts to 2.0 or web application or programs enabling each user to be able not only to retrieve information in the form of texts, pictures, and video clips but also to connect to one another on web pages. [6] And this kind of online communication technology has become 'social media'. The convenience and charm of social media capture the attention, and consume much longer time of more and more internet users. Based on the survey by The Office of Electronic Transactions Development Agency, Bangkok, Thailand, it is found that Generation Y internet users or those with 15-34 years of ages are the group spending their time on the Internet in highest level - with the average of 54.2 hours a week or 7.2 hours a day. [7]

Based on these findings, it can be concluded that university students who are in Generation Y spend more of their time on the Internet than on formal classroom learning which takes about 21 hours per week as in the university regulation. [4] However, the most common language used on the Internet is English language. Ongoing monitoring by W3Techs showed that in March 2015, just over 55 percent of the most visited websites had English-language homepages. [8] The assumption is that students use some English while surfing the Net or during their time consumption on the Internet outside the classroom. They probably learn or at least practice using English informally and independently on the Net while spending their time outside the classroom.

Meanwhile, the development of Information Communication Technology and social media affect the teaching of English in some aspects. In classroom contexts, some electronic learning management systems allow English language learners to learn from a variety of multimedia and online learning resources with pictures, texts, sounds, YouTube, etc. both in class and outside class while teachers can make use of the new media to facilitate learning and teaching in more dynamic ways. Communication between teachers and students or students and students take place not only in the classroom setting but also on web-blogs, facebook, etc. The teaching methodologies have been changed from the so called "Talk and Chalk" or lecture to "Point and Click" teaching or teaching with multimedia presentation. Moreover, "Task-based learning" and "Project-based activities" have 
become common and efficient by the use of the Internet. [9] It is, therefore, common for teachers to assign students to engage with English outside the class and bring into the class the authentic English in the forms of reports or classroom presentation. At the same time, students upon their own interest and the drive of being up to date with social media spend most of their time on the Internet. [9] However, by ignoring what students do with English outside the classroom or paying no attention to students' engagement with English outside the classroom or social media-based activities most conducted in English by the students, teachers will never truly understand their needs and never fully realize the benefits and charm of social media as a language learning tool. The purposes of this study are 1) to find out the amount of time the students spend on the Internet per day, and 2) to study the social media-based activities most frequently conducted in English by the students.

\section{THEORETICAL BACKGROUND}

\section{A. The Importance of Using English outside the Classroom}

In terms of classroom language instruction, learning materials and learning resources include exercises, examples, contents, and tasks with authentic language used outside the classroom, such as notices, advertisements, news from daily newspapers, articles from journals, various TV programs, movies, etc. Moreover, task-based learning activities or learner's based activities require students to retrieve information outside classroom and make presentation or write report for classroom learning. This is also a way to bring authentic language to be learned in classroom contexts. [10] The purposes of bringing real English outside classroom for classroom language instruction either by teachers or students are to motivate and prepare learners to use English in daily life for communication in various contexts, and to learn English meaningfully. That is because learning and practicing English from authentic language and contexts enable learners to acquire the language and be able to use in the future. [11] However, bringing authentic English for classroom language instruction is like bringing pieces or parts of language used outside the classroom for learning purposes in classroom.

In classroom of countries learning English as a foreign language like Thailand, using English outside classroom is quite rare since official language is Thai language and most people speak their mother language in daily life. The chance to use English for students in Thailand is in classroom contexts or in activities assigned by teacher of English. On the other hand, in classroom of countries learning English as a second language like Philippines and India, where official language of these countries is English, students can use English both in the classroom a nd outside the classroom. More chances to use English lead to higher proficiency of English of students learning English as a second language. [12] However, thanks to fast growing Information Communication Technology and the popularity as well as the convenience of using social media to connect to the world, nowadays internet users spend long hours on the Internet. As core language used on the Internet is English, these Internet users including students in Thailand have more chances to be exposed to English outside the classroom. [2] They can watch their favorite movies and cartoons with English soundtrack from websites. They can enjoy watching music video of the top 10 songs on the latest billboard chart from websites and even more they can learn the meaning of songs from lyrics of their favorite songs from websites. These examples disclose chances students can use English outside the classroom and it can be assumed that while spending their time on the Internet, students are exposed to authentic English. Moreover, if teachers of English can bridge the English available on social media with classroom language instruction or vice versa, learning English will be enriched by the use of social media a magic tool for the Internet users. This state of the art technology will become a magic tool for English language learners and teachers, as well.

\section{B. 'Social Media' and 'Student's time Consumption outside the Classroom'}

The term 'social media' is frequently mentioned in various contexts with different meaning. Here are some definitions. The use of social media has changed people's communicative patterns over the last 10 years by enabling users "to create, distribute, share and manipulate different types of content, most of them publicly accessible". [9] "Social Media" is defined as online media enabling users to interact with one another online through various web application allowing users to create, distribute, share and manipulate a variety of contents including texts, pictures, video, songs, etc. to other net-users, and these contents can be accessible publicly. Social media investigated in this study include blogs, YouTuble, Twitter, Instragram, Line, etc.

"Student's time consumption outside the classroom" or "Students Engagements" with English outside the classroom can be defined as how students use English language to achieve a language function outside the classroom. Using English outside the class does not simply mean studying more, but it refers to using English to reach the students' own goals, such as to watch cartoon with English soundtrack for their enjoyment, to use English-English dictionary to solve linguistic problems, etc. It can be noted that students' time consumption outside the classroom can be carried out both through social media or printed and multimedia materials. For example, in the case of watching cartoon, it can be done by using social media like from websites or from CD or TV. Moreover, there are more options for using English-English dictionary, such as online or printed dictionary, and websites or application serving as a dictionary.

In this study, student's time consumption outside the classroom is, therefore, focused on how students use English outside the classroom by using a variety of materials from social media or social media-based activities in English.

Since today it is perceived that internet users including students spend long hours on the Internet using social media each day, it is essential to find out how long most students spend their time on the Internet, and what language functions most frequently conducted by using social media.

\section{RESEARCH DESIGN}




\section{A. Samples and Procedures}

Samples of this study are 78 3rd year English major students, English language program, Faculty of Humanities and Social Sciences, Suan Sunandha Rajabhat University, Bangkok, Thailand. Data is collected by using a 5-scale questionnaire which has been verified and tried out. Here are the details of the 5 rating scales.

TABLE I: DETAILS OF THE 5 RATING SCALES

\begin{tabular}{ll}
\hline \hline Level of frequency & Description \\
\hline 5 highest level & More than 8 hours a day \\
4 high level & Average 6-8 hours a day \\
3 medium level & Average 4-6 hours a day \\
2 low level & Average 2-4 hours a day \\
1 lowest level & Less than 2 hours a day \\
\hline \hline
\end{tabular}

Table I shows details of the 5 rating scales. The amount of time provided in the scales is in line with the research findings revealed by the Office of Electronic Transactions Development Agency, Bangkok, Thailand. [7]

The questionnaire includes 34 items containing language functions or activities students accomplish outside the classroom during their engagement with English outside the classroom. These functions are divided into 2 groups; language functions accomplished during the engagement with English outside the classroom 1) through either social media tools or printed and multimedia materials, and 2) through only social media or social media-based activities in English. The questionnaire is used to ask 3rd year English major students to rate the frequency of their engagements per day.

\section{B. Research Questions}

Based on the purposes of this study including to find out the amount of time the students spend on the Internet per day, and to study the social media-based activities most frequently conducted in English by the students, the research questions are as follows;

1) How long do most students spend their time on the Internet outside the classroom per day?

2) What social media-based activities do the students achieve during their engagements with English outside the classroom? And to what extent is each activity used?

\section{RESULTS}

Based on the research results, the study discloses the amount of time the students spend on the Internet per day, and the social media-based activities most frequently conducted in English by the students. The details of the findings are as follows;

\section{A. The Amount of Time the Students Spend on the Internet}

TABLE II: TIME CONSUMPTION ON THE INTERNET

\begin{tabular}{ll}
\hline \hline Amount of time per day & Percentage \\
\hline More than 8 hours & 29.19 \\
6-8 hours & 37.18 \\
4-6 hours & 20.51 \\
2-4 hours & 10.26 \\
Less than 2 hours & 2.56 \\
\hline \hline
\end{tabular}

Table II shows the amount of time 3rd year English major students spend on the Internet per day. Most of the students or 37.18 percent spend 6-8 hours a day on the Internet each day while 29.19 percent spend more than 8 hours a day, 20.51 percent spend 4-6 hours a day, 10.26 percent spend 2-4 hours, and 2.56 percent spend less than 2 hours respectively.

It can be concluded that most of the students spend 6-8 hours a day on the Internet, and this finding is in line with the findings revealed by The Office of Electronic Transactions Development Agency, Bangkok, Thailand stating that most Generation Y internet users or people with spend average 7.2 hours per day on the Internet. [7] This amount of time is high comparing to the time the students spend in the classroom in a day. It is, therefore, necessary for teachers and course developers to rethink about teaching methodology, which pay more emphasis on learning activities supporting and encouraging the students' engagement with English outside the classroom and finding way to bridge social media-based activities with classroom language instructions so that the amount of time the students spend on the Internet will result in some extent of English language learning.

\section{B. Social Media-Based Activities}

TABLE III: SOCIAL MEDIA-BASED ACTIVITIES

\begin{tabular}{|c|c|c|c|c|}
\hline No. & Activities & Mean & S.D. & Level \\
\hline 1 & $\begin{array}{l}\text { Watching cartoons with English } \\
\text { soundtrack from websites }\end{array}$ & 4.17 & 1.00 & high \\
\hline 2 & $\begin{array}{l}\text { Using online dictionary to solve } \\
\text { linguistic problems }\end{array}$ & 3.75 & 1.10 & high \\
\hline 3 & $\begin{array}{l}\text { Reading comments in English } \\
\text { from online blogs or forums for } \\
\text { pleasure }\end{array}$ & 3.63 & 1.42 & high \\
\hline 4 & $\begin{array}{l}\text { Watching online entertainment } \\
\text { and documentaries in English }\end{array}$ & 3.45 & 1.22 & high \\
\hline 5 & Reading online news in English & 3.38 & 1.27 & medium \\
\hline 6 & $\begin{array}{l}\text { Practicing doing online English } \\
\text { exercises and exam }\end{array}$ & 3.35 & 1.18 & medium \\
\hline 7 & $\begin{array}{l}\text { Watching online TV program in } \\
\text { English }\end{array}$ & 3.35 & 1.03 & medium \\
\hline 8 & $\begin{array}{l}\text { Using websites or application to } \\
\text { solve linguistic problems }\end{array}$ & 3.33 & 1.37 & medium \\
\hline 9 & Creating private blog in English & 3.31 & 1.27 & medium \\
\hline 10 & $\begin{array}{l}\text { Joining online private English } \\
\text { lessons }\end{array}$ & 3.08 & 1.16 & medium \\
\hline 11 & $\begin{array}{l}\text { Reading articles from websites } \\
\text { for pleasure }\end{array}$ & 3.04 & 1.33 & medium \\
\hline 12 & $\begin{array}{l}\text { Reading and translating lyrics of } \\
\text { songs in English for pleasure }\end{array}$ & 2.99 & 0.11 & medium \\
\hline 13 & $\begin{array}{l}\text { Using social media for } \\
\text { communication in English }\end{array}$ & 2.95 & 1.22 & medium \\
\hline 14 & $\begin{array}{l}\text { Learning English from the } \\
\text { University online learning } \\
\text { resources }\end{array}$ & 2.91 & 1.27 & medium \\
\hline 15 & $\begin{array}{l}\text { Retrieving information in } \\
\text { English for pleasure }\end{array}$ & 2.77 & 1.15 & medium \\
\hline 16 & $\begin{array}{l}\text { Playing online game with } \\
\text { English instruction }\end{array}$ & 2.73 & 1.16 & medium \\
\hline 17 & $\begin{array}{l}\text { Retrieving information in } \\
\text { English for academic purposes }\end{array}$ & 2.30 & 1.09 & low \\
\hline 18 & $\begin{array}{l}\text { Watching movies with English } \\
\text { soundtrack from websites }\end{array}$ & 2.19 & 1.00 & low \\
\hline 19 & $\begin{array}{l}\text { Listening to English songs from } \\
\text { YouTube }\end{array}$ & 1.81 & 0.40 & low \\
\hline
\end{tabular}

Based on the research findings, here are some social 
media-based activities most frequently conducted in English by 3rd year English major students.

Table III shows 19 social media-based activities conducted in English by 3rd year English major students. There are 4 social media-based activities most frequently conducted by the students in high level which is 6-8 hours a day. The activity with highest mean scores includes watching cartoon with soundtrack in English from websites followed by using online dictionary to solve linguistic problems, reading comments in English from online blogs or forums for pleasure, and watching online entertainment and documents in English respectively. Moreover, 12 out of 19 social media-based activities are conducted in English in medium level which is 4-6 hours a day, and 3 out of 19 social media-based activities are conducted in low level which is 2-4 hours per day.

Based on these findings, it can be noted that social media-based activities are conducted in English for pleasure as well as for academic purposes. Social media-based activities conducted in English are for pleasure more than for academic purposes. Social media-based activities conducted in English for pleasure include watching cartoon with soundtrack in English from websites, reading comments in English from online blogs or forums for pleasure, watching online entertainment and documents in English. However, only 6 social media-based activities conducted in English for academic purposes include using online dictionary to solve linguistic problems such as translation, and pronunciation, practicing doing online English exercises and exam, using websites or application to solve linguistic problems, joining online private English lessons, learning English from the University online learning resources, and retrieving information in English for academic purposes.

\section{Discussion AND SUGGeSTION}

Based on the research findings, the impact of social media on the students' time consumption can be divided into 2 points; its impact on 1) students' learning behavior, and 2) students' skills relating to social media.

\section{A. Students' Learning Behavior}

In the past most teachers and parents think that English language learners especially English as a Foreign Language learners lack the opportunities to use English outside the classroom due to the contexts of countries not using English as official language. The only place these learners will learn English is in English language classrooms. However, the research findings reveal 19 social media-based activities conducted in English by the students without having to face with native speakers of English. These communicative language activities range from watching cartoon from websites, practicing English through online exercises and tests, retrieving information from websites in English for pleasure, reading comment in English from blogs, forums, creating their own private blogs and forums in English. Moreover, the average amount of time spent on these activities is in medium level; 4-6 hours per day. The findings show the students' willingness to use English independently for pleasure and for academic purposes. However, it is advisable that more emphasis should be placed on motivating the students to conduct social media-based activities in English for academic purposes.

Moreover the above social media-based activities are authentic, meaningful, and fascinating so much to the students that the students autonomously manage themselves to achieve these functions without the traditional teachers' assignment. [9] Social media, therefore, plays vital roles on this kind of self-regulated learning because of its immediate feedback, its availability anywhere, anytime, its convenience and its capability to allow connection and sharing among other net-users.

\section{B. Students' Skills Supported by Social Media}

The research findings reveal some students' skills supported by the use of social media. It can be noted that based on social media-based activities, receptive skills; reading and listening skills are mostly employed. [12] For example, watching cartoon with English soundtrack on websites can not only entertain the students, but also expose the students to authentic English used in various situations. Moreover, online dictionary and web application help develop the students' ability to use linguistic resources and media tools to understand English in authentic communicative contexts. That is because this communication technology is convenient to use and it is a kind of mobile tool satisfying the internet users to use their mobile phones for learning purposes.

Moreover, since "Line" is the most frequently used social media, writing skills and creative thinking skills can be supported by this kind of social media. Thinking skills can, also, be challenged when the students play some online games. [9] It can be concluded that language skills; receptive skills like listening and reading with dictionary skills and writing skills with creative thinking skills can be supported by the use of social media.

For language teachers, it is advisable to use social media as a language tool. For example it's a good opportunity for language teachers to share their experiences, tips and resources through social media. Moreover, teachers can engage with students on social media, such as creating a Facebook page, or blog for the class to access lesson plans, learning and teaching materials, quiz, samples of report, etc.

It's also language teachers' job to bridge the outside world to classroom by designing tasks allowing students to bring into class variety of contents in the form of project based learning or learner's based activities. Furthermore, let students create some cultural contents and share them to the world through social media. However, the important role of language teachers is to facilitate the students about the language accuracy and to challenge the students with the use of language outside the classroom using appropriate social media.

It is unavoidable that social media becomes part of our daily life and learning environment. Based on the research findings, a high percentage of students use social media. Yet, a closer look at social media-based activities reveals a focus on receptive rather than productive language skills. The use of social media has changed the students' communicative pattern and behaviors. They are more willing to engage with 
English outside the classroom due to the fascination of social media enabling the internet users to be more easily linked on a more global scale, to be able to distribute, share and let oneself known publicly. Moreover, social media can support some kinds of language learning. It is, therefore, suggested that language teachers should allow the implementation of social media in teaching and make use of it in designing tasks challenging the students to bring in contents as well as social media tools for language learning purposes. Teachers are also required to encourage and facilitate learners to collect and create relevant content, resources into a meaningful collection of virtual space, to construct and create new knowledge and understanding through blogs, Slideshares presentation, Wikis, etc., and to share these work and communicate with others.

\section{CONCLUSION}

It is unavoidable that social media becomes part of our daily life as well as learning environment. The impact of social media on students' time consumption outside the classroom includes the average amount of time 3rd year English major students spend on the Internet per day, which is 6-8 hours per day. It is more than the time they spend learning in class per day. However, since English language is core language used for communication on the Internet. It is found that the students engage with some English while spending their time on the Internet. That is they spend average 6-8 hours per day involving in social media-based activities, such as watching cartoons with English soundtrack from websites, using online dictionary to solve linguistic problems, reading comments in English from online blogs or forums for pleasure, and watching online entertainment and documentaries in English. It can be noted that while spending their time on the Internet, they use English for pleasure more that for academic purposes. It is suggested that language teachers should allow the implementation of social media in teaching and making use of it in designing tasks challenging the students to bring in contents as well as social media tools for language learning.

\section{ACKNOWLEDGMENT}

This is in the acknowledgment of funding by Suan Sunandha Rajabhat University personal development fund for the oral presentation at 4th International Conference on Behaviors, Education, and Psychology, San Francisco, USA, from October 23th - 25th, 2016.

\section{REFERENCES}

[1] D. Crystal, English as a Global Language, Cambridge: Cambridge University Press, 1997.

[2] Usage of content languages for websites, W3Techs 2016. [Online]. W3Tech Web Technology Survey. Available: https://w3techs.com/technologies/overview/content_language/all
[3] J. Melitz. (June 2009). English as a global language: Good for business, bad for literature. Center for Economic Policy Research. [Online]. Available: http://www.file://F:IEnglishasthegloballanguage.html

[4] W. Kunnu, "Teaching speaking skills to adult English language learners through ALM," International Journal of Social Behavioral Education, Economic and Management Engineering, pp. 277-287, vol 20/14, 2013.

[5] S. Metzger, "Why the texting generation is actually the lonely generation," Elite Daily.

[6] R. O. Gibson. (April 2012). Using social media as a language learning tool. The Guardian. [Online]. Available: https://www.theguardian.com/teacher-network/teacher-blog/2012/apr/ 10/language-teaching-social-media

[7] Thailand Internet Users Profile, 2015, Electronic Transactions Development Agency (Public Organization) ETDA Report, Bangkok, Thailand, 2015.

[8] P. Sayer and R. Ban, "Young EFL students' engagement with English outside the classroom," English Language Teaching (ELT) Journal, pp. 321-329, vol. 68, no. 3, 2014.

[9] K. Zourou, "On the attractiveness of social media for language learning: A look at the state of the art," Alsic, vol. 15, no. 1, 2012.

[10] R. S. Davis and H. Armstrong, "Using a foreign language beyond the classroom," The Language Teacher, pp. 52-55, vol. 19, no. 5.

[11] A. Paran, "Language skills: Questions for teaching and learning," English Language Teaching (ELT) Journal, pp. 450-458, vol. 66, no. 4.

[12] M. Miglbauer and T. Kotikoski. (May, 2015). Students' use of English outside the classroom and its impact on teaching the four skills: A best practice example of an online writing project. Language Teaching Tomorrow. [Online]. Available: http://urn.fi/urn:nbn:fi:jamk-issn-2343-0281-2

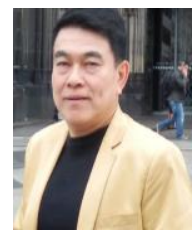

Chaiwat Tantarangsee was born in Ratchaburi province, Thailand in 1955. He received his bachelor's degree in education majoring in teaching English, Chulalongkorn University, Bangkok, Thailand, 1976. He received his master's degree in education in teaching English as a foreign language, Chulalongkorn University, Bangkok, Thailand, 1993. He started his career in teaching English in a secondary school, Ratchaburi, Thailand, in 1997, and had experiences in teaching English in secondary school level for 16 years. From 2002 up to now he has been an assistant professor in English language program, Faculty of Humanities and Social Sciences, Suan Sunandha Rajabhat University, Bangkok, Thailand. He has been published several articles in international journals.

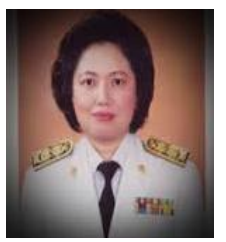

Nithiwadee Kosarussawadee was born in Phitsanulok, Thailand in 1966. She received her bachelor's degree of arts majoring in English, Chulalongkorn University, Bangkok, Thailand, 1987. She received her master's degree of arts in linguistics, Chulalongkorn University, Bangkok, Thailand, 1990. She started her career in teaching English at the Department of Foreign Languages at the Faculty of Humanities and Social Sciences, Pibulsongkram Teacher's College from 1990 to 1995 . The she moved to Suan Sunandha Rajabhat University, Bangkok in 1995 and has been working here up to now.

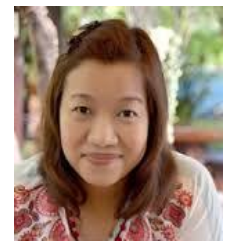

Aungkana Sukwises was born in Bangkok, Thailand in 1976. She received her bachelor's degree of arts majoring in English language and literature, Thammasat University, Bangkok, Thailand, 1996. She received her master's degree of arts in comparative literature, Chulalongkorn University, Bangkok, Thailand, 2001. She started her career in teaching English in English language program, Faculty of Humanities and Social Sciences, Suan Sunandha Rajabhat University, Bangkok, Thailand from 2000 up to now. 